\title{
The comprehensive evaluation of water resources condition
}

\author{
Ben Niu, a \\ ${ }^{1}$ School of North China Electric Power University, Baoding 071000, China \\ a2676190951@qq.com
}

Keywords: AHP, DPSIR, the Entropy model.

\begin{abstract}
Analytic Hierarchy Process(AHP)Model is established to determine the weight of each indicator to evaluate the water scarcity. Then the Entropy model is built to overcome weakness of excess subjective factors in AHP. By using Product integration method to combine two models, we determine the final indicators weights and apply those into the DPSIR model to calculate CEI of 18 main countries and classify those into 4 levels. As far as CEI is concerned, the bigger, the better. According to relevant documents, our ranking results are fairly credible.
\end{abstract}

\section{Introduction}

The world runs on water. Clean reliable water supplies are vital for industry, agriculture and energy production. Yet the world's water systems face formidable threats. More than a billion people currently live in water-scarce regions, and as many as 3.5 billion could experience water scarcity by 2025[1]. The increasing pollution, rates of industrial consumption and personal consumption degrades freshwater and coastal aquatic ecosystems. And climate change is poised to shift precipitation patterns and intensifying floods and drought. The water scarcity has become one of the most pressing issues in the world.

\section{Model for the sustainability of countries}

We set up a model to ensure the weight of indicators based on Analytic hierarchy process (AHP) and the entropy method.

We defined comprehensive evaluation index (CEI) which measure the ability of a region or countries to provide clean water to meet the needs of its population. Through our model, as long as we know the relevant data of a region or country, it is capable for us to calculate the comprehensive evaluation index exactly, and then we can judge if the country is in the water scarcity or not. Moreover, we also set up the source of water index, the water consumption index and other indexes related to fresh water to find out what has blocked the ability of a region to provide clean water, which is useful for us to determine policies as well as provide assistance.

\subsection{Specify evaluation norms preliminary}

As mentioned on Problem E, There are two primary causes for water scarcity: physical scarcity and economic scarcity. Based on those causes, we divide reasons of water scarcity into three parts which are the first components: the source of water factors set, the water assumption factors set and other factors set at first. By collecting 27 indicators related to those three parts, we created the second components.

\subsection{Two models for the weight of multiple indicators}

\subsubsection{Model one: Analytic Hierarchy Process (AHP)}

The three-hierarchy structure

The four hierarchy structure which contains criteria level and alternative level is shown in following table. 
Table 1 . The four hierarchy structure of our model

\begin{tabular}{|c|c|c|c|}
\hline Goal & Criteria I & Criteria II & Alternatives \\
\hline & & Rainfall & Long-term average precipitation in depth \\
\hline & & Surface & Surface water produced internally \\
\hline & generation & $\begin{array}{c}\text { water } \\
\text { Underoroun }\end{array}$ & Groundwater nroduced internally \\
\hline & & $\begin{array}{l}\text { d } \\
\text { water }\end{array}$ & Grounawater produced internany \\
\hline $\begin{array}{c}\text { The } \\
\text { scarcity }\end{array}$ & $\begin{array}{l}\text { The } \\
\text { consumptio }\end{array}$ & Agriculture & $\begin{array}{c}\text { Cultivated area (arable land + permanent } \\
\text { crops) }\end{array}$ \\
\hline of water & $\mathrm{n}$ & & $\begin{array}{c}\cdots \\
\text { Inductrial water withdrawal }\end{array}$ \\
\hline $\mathrm{s}$ & of water & Industry & 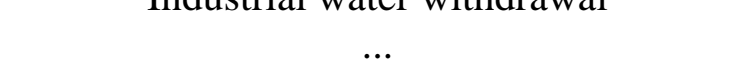 \\
\hline & & Ponulation & Total area \\
\hline & & & $\cdots$ \\
\hline & & Economy & Gross Domestic Product (GDP) \\
\hline & Others & & $\cdots$ \\
\hline & & Others & Total internal renewable water resources per \\
\hline & & & $\ldots$ \\
\hline
\end{tabular}

\subsubsection{Model two: the method of entropy}

On account of subjectivity of AHP, we introduce the method of entropy[2] which is more objective. The principle of entropy method stats that, subject to precisely stated prior data, the probability distribution which best represent the current state of knowledge is the one with largest entropy.

\subsubsection{Model combination}

AHP is a subjective method, it largely depends on artificial scoring; Entropy is an objective method, it all depend on data. To comprehensively consider the effect of subjective and objective factors, we adopt linear weighted method.

\section{Results \& analysis}

By recalculating the weights of 17 indicators, the comprehensive weight of each indicator is showing as follow:

Table 2. The weight comparison among the models

\begin{tabular}{|c|c|c|}
\hline $\begin{array}{c}\text { The ranking of } \\
\text { weight }\end{array}$ & indicator & weight \\
\hline 1 & $\begin{array}{c}\text { Industrial water withdrawal of total } \\
\text { water withdrawal }\end{array}$ & 0.1968 \\
2 & Total renewable groundwater & 0.1321 \\
3 & Human Development Index (HDI) & 0.1075 \\
\hline$\ldots$ & $\ldots$ & $\ldots$ \\
15 & $\begin{array}{c}\text { Agricultural water withdrawal of } \\
\text { total renewable water resources }\end{array}$ & 0.0168 \\
16 & $\begin{array}{r}\text { Cultivated area } \\
17\end{array}$ & $\begin{array}{r}\text { Water resources: total external } \\
\text { renewable }\end{array}$ \\
\hline
\end{tabular}

$\sqrt{ }$ The ranking of comprehensive weights are very similar to the AHP in top 5

$\sqrt{ }$ According to our final result, our model's top 3 indicators which have lager influence on the water scarcity are industrial water withdrawal of total water withdrawal, total renewable 
groundwater, human Development Index (HDI).

\subsection{The evaluation of regional water scarcity under the DPSIR framework}

\subsubsection{DPSIR analysis approach}

The evaluation framework of the water scarcity based on the DPSIR model which contains five parts: driver, pressure, state, impact and respond. By referring the standard definitions and online expert's thoughts about the indicators we collected, we divided multiple indicators into five categories[3].

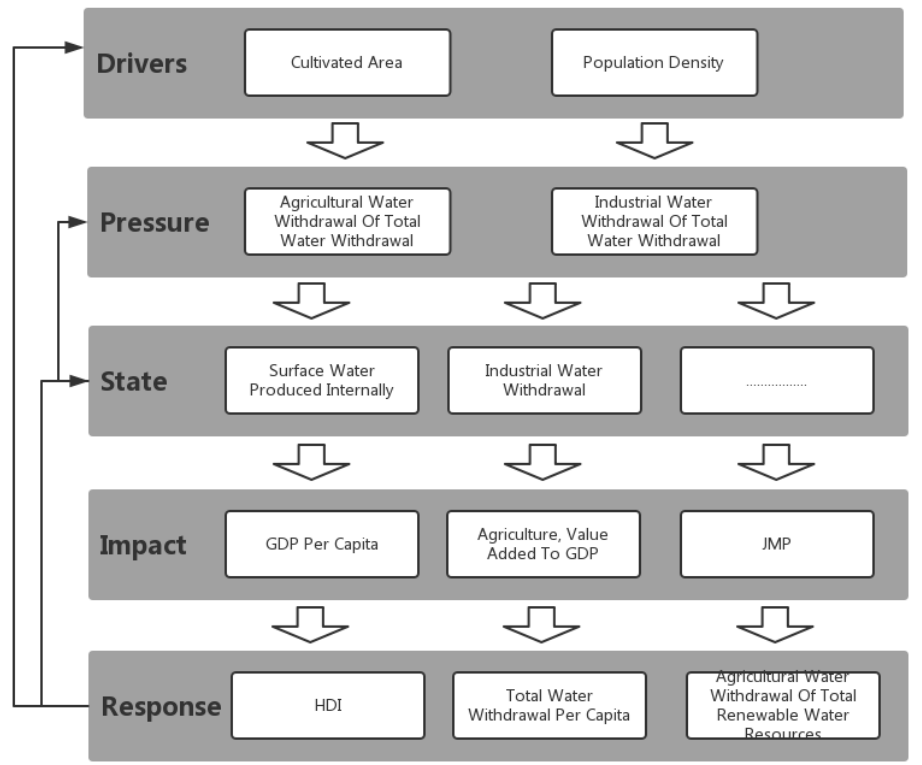

Fig.1 The framework of DPSIR in evaluating the water scarcity

\section{The weight of the indicators in the DPSIR framework}

Based on the AHP model and the method of Entropy, we have got the weights of indicators which are distributed into D,P,S,I,R those five comprehensive factors.

\section{Calculate comprehensive factors}

The contribution rate of D,P,S,I,R those five comprehensive factors to the comprehensive evaluation index of the water scarcity is different, as well as the influence of the second indicators on each comprehensive factor. So we use the comprehensive index method to calculate the value of comprehensive factors[4].

\subsubsection{Results\&analysis}

The comprehensive evaluation value which shows the ability of a region or country to provide the fresh water to meet the needs of its population is shown as follow:

Table 3. The values of comprehensive evaluation indexes in 18 typical countries.

\begin{tabular}{|c|c|c|}
\hline $\begin{array}{c}\text { Ranking of the water } \\
\text { producing ability }\end{array}$ & Country & CEI \\
\hline 1 & Germany & 0.2387 \\
2 & Canada & 0.2254 \\
3 & United States of America & 0.2189 \\
4 & India & 0.2042 \\
5 & China & 0.1878 \\
$\ldots$ & $\ldots$ & $\ldots$ \\
\hline 12 & Afghanistan & 0.1221 \\
\hline$\ldots$ & Kazakhstan & 0.122 \\
\hline 18 & $\ldots$ & $\ldots$ \\
\hline
\end{tabular}

By referring to the method of dividing the situation of the water scarcity, we make a connection 
with the comprehensive evaluation and the level of the water scarcity, determine the Classification threshold of each level which is applied to evaluate the water scarcity in specific region.

We referring the data from Vital Water Graphics to evaluate the accuracy of our results.

\section{Summary}

Take Kazakhstan as an example, the threshold of Kazakhstan 0.122 is between 0.12 and 0.13 is be regarded as relative lack of water.

The relationship between main indicators of the water scarcity and the Seasonal and uncertainty indicators are concluded and discussed in DPSIR model, for example the change of seasonal indicators such as the decrease of precipitation in Winter which is concluded into State will reduce the supply and decrease the comprehensive evaluation index of the water scarcity.

\section{References}

[1] http://www.wri.org/our-work/topics/water

[2] Dahiya S, Singh B, Gaur S, et al. Analysis of groundwater quality using fuzzy synthetic evaluation[J]. Journal of Hazardous Materials, 2007, 147(3): 938-946

[3] European Commission. Common implementation strategy for the Water Framework Directive (2000/60 EC)

[4] Jiquan Zhang, kunpeng Yi, Hiroshitani,et al. Ecological security assessment of Baishan City in Jilin Provice based on DPSIR[J].Chinese Journal of Applied Ecology, Jan. 2011, 22(1); 189-195 